\title{
Scenario Model to Mitigate Traffic Congestion and Improve Commuting Time Efficiency
}

\author{
Shabrina Luthfiani Khanza ${ }^{1)^{*}(D)}$, Erma Suryani ${ }^{2)}$ (D), Rully Agus Hendrawan ${ }^{3)}$ (D) \\ ${ }^{1) 2) 3)}$ Department of Information Systems, Institut Teknologi Sepuluh Nopember, Indonesia \\ Jl. Teknik Kimia, Keputih, Sukolilo, Surabaya \\ ${ }^{1)}$ luthfianisk@gmail.com, ${ }^{2)}$ erma.suryani@gmail.com, ${ }^{3)}$ ruhendrawan@gmail.com
}

\begin{abstract}
Background: Commuting time is highly influenced by traffic congestion. System dynamics simulation can help identify the cause of traffic problems to improve travel time efficiency.

Objective: This study aims to reduce traffic congestion and minimise commuting time efficiency using system dynamics simulation and scenarios. The developed scenarios implement the Bus Rapid Transit (BRT) and trams projects in the model. Methods: System dynamics simulation is used to analyse the transport system in Surabaya and the impact of BRT and trams project implementation in the model in order to improve commuting time and to reduce congestion.

Results: From the simulation results, with the implementation of BRT and tram projects along with highway expansion, traffic congestion is predicted to decline by $24-44 \%$. With the reduction of traffic congestion, travel time efficiency is predicted to improve by $11-28 \%$. On the contrary, implementation of BRT and tram project without highway expansion is predicted to increase the traffic congestion by $5 \%$ in the initial year of implementation, then traffic congestion is predicted to decline by $2 \%$ in 2035 .

Conclusion: Based on the scenarios, transport project implementation such as BRT and trams should be accompanied with improvement of infrastructure. Further research is needed to develop a more comprehensive transportation system to capture a broader view of the problem.
\end{abstract}

Keywords: Model, Simulation, System Dynamics, Traffic Congestion, Travel Time

Article history: Received 28 Juli 2021, first decision: 19 August 2021, accepted 23 September 2021, available online 28 October 2021

\section{INTRODUCTION}

Traffic congestion is described as overloaded vehicles on a part of the roadway at a critical time resulting in speeds slower than free-flow speed [1], [2]. Traffic congestion or degree of saturation represents a comparison of traffic flow and road capacity [3]. The relationship between traffic flow and travel time is described as a function 'if traffic flow increases, the commuting time will increase exponentially' [4]. The efficiency is a comparison of the actual travel time with the expected travel time [5]. The relationship between traffic congestion and commuting time can be expressed as a function: 'if the congestion increases the travel time will also increase' [6]. Based on the above issue, it is necessary to reduce congestion to improve commuting time efficiency. Reducing commuting time will definitely increase city dwellers' productivity and both physical and mental health[7].

System dynamics help to identify and verify the cause of traffic problems. System Dynamics (SD) is a model development approach in studying a system's complexity and dynamic behaviour [8]. The structure of an SD modelling is represented by a Causal Loop Diagram [9]. The model created can be tested based on the impact of the strategies and conditions applied to the system [10]. It reflects changes through causal relationships between variables by positive or negative impacts; and can be tested through simulations where the outcomes are known by changing or modifying various existing parameters and variables [11]. Simulations are frequently used in studies due to the wide variety of inputs and they have several advantages over mathematical models because they can be experimented with without any real risk to the system.

This research aims to formulate relationships between several variables related to commuting time efficiency, modelling the dynamic behaviour of commuting time and traffic congestion, and developing scenario models to improve commuting time efficiency and reduce traffic congestion. Some references regarding travel time and traffic

\footnotetext{
${ }^{*}$ Corresponding author
} 
congestion were used as basic knowledge in building the model. The structural scenario tested and evaluated potential strategies to increase commuting time efficiency and reduce traffic congestion. The scenario development includes Bus Rapid Transit (BRT) and tram projects based on the plan of the Surabaya City Government. We develop the model and scenario as generic as possible so that the model and scenario can be implemented in other cities by modifying the model parameter based on where the case study will be conducted.

\section{METHODS}

\section{A. Problem formulation}

Cities have been facing traffic congestion for a long while, with hotspots found near the centres of economic activities such as shopping malls. In Surabaya, this happens along Urip Sumoharjo Street as it is one of the main accesses to the city centre. The travel time in 500-metre long Urip Sumoharjo street should take around 30 seconds, but it can take up to 2 minutes or more in high traffic jams. When accumulated, commuting time is at least doubled. This also impacts the flows on Darmo Street and Panglima Sudirman Street. The proposed solutions by the Surabaya City Government include BRT and tram project. Surabaya will also build Surabaya Mass Rapid Transit (SMART) consisting of tram and monorail as new transportation modes to reduce congestion [12]. The implementation of bus rapid transit (BRT) also received positive responses from Surabaya citizens, but it only lasted from September to December 2016. BRT was considered suitable for the condition in Surabaya, and it was more affordable and faster than rail-based transportation.

The use of model validation is required to ensure that the actual system is well represented. After the model is valid, scenario is developed based on the proposed strategy. Scenario development allows for hypothesis of the future model behaviour to be tested [13], as well as the indicators that affect commuting time efficiency and the congestion levels. The ultimate goal is to discover which scenario that can reduce congestion most effectively thus improving the commuting time efficiency. The scenarios are: 1) BRT and tram project with highway expansion; and 2) BRT and tram project without highway expansion.

The data used in this study were collected from the Transportation Department of Surabaya and the Central Bureau of Statistics. The type of vehicles considered in this study include motorcycle, private car, shared taxi car, minibus, boxcar, non-motorised vehicle, large bus, truck, and trailer. The identified variables that influence commuting time efficiency are commuting time, commuting time delay, commuting time in free flow and traffic congestion. The observed roadway, Urip Sumoharjo, is one of the routes that would be affected by the implementation plan of the BRT and tram project. The software used for the model development is Vensim PLE.

\section{B. Dynamic hypothesis}

Commuting time was calculated using the IHCM Volume Delay Formula (VDF) which proved to be more accurate than the United States Bureau of Public Roads (BPR) VDF [3], [14]. Commuting time in IHCM VDF can be expressed in Equation (1) as follows:

$$
\mathrm{T}=\mathrm{T}_{0}+\alpha_{1} \cdot\left(\frac{Q}{C}\right)^{\beta}+\alpha_{2} \cdot\left(\frac{Q}{C}\right)
$$

where $T$ is commuting time in minutes, $T_{0}$ is commuting time in free flow in minutes, $Q$ is traffic volume in passenger car unit per hour, $C$ is road capacity in passenger car unit per hour, and parameter $\alpha_{1}, \alpha_{2}, \beta$.

A Causal Loop Diagram (CLD) represents the causal relationship between variables in the model [15]. CLD's main function is to display the causal hypothesis of each variable so that it can be represented in a better structure [16]. CLD in Fig. 1 has two reinforcing loops (R1 and R2) and two balancing loops (B1 and B2). Reinforcing feedback loop identifies the changes in a connection are in the same direction, while balancing feedback loop shows the changes in the opposite [17]. An increase in traffic per hour increases traffic congestion (R1). An increase in commuting time delay will decrease the delay performance and vice versa (R2). An increase in delay performance will decrease the commuting time delay; an increase in commuting time delay will increase the commuting time; and an increase in commuting time will reduce delay performance (B1).

Vehicle volume is the accumulation of the vehicle variables: Motorcycle, Private Car, Shared Taxi Car/Minibus/Box/Other, and Bus/Truck/Trailer. Motorcycle and Private Car variables represent the numbers of motorcycles and the number of private cars respectively. Shared Taxi Car/Minibus/Box/Other variables represent the numbers of non-private vehicles that are included in light vehicles such as shared taxi cars, minibuses, mini trucks, boxcars, and non-motorised vehicles. The Bus/Truck/Trailer variable shows non-private heavy vehicles, such as large buses, trucks and trailers. The Traffic per Hour variable shows that amount of traffic per hour per day. Surabaya population is required to determine the value of City Size Adjustment Factor for road capacity. Road Capacity is the 
multiplication result of Basic Capacity, Road Width Factor, Factor of Separated Way, Side Friction Factor and City Size Adjustment Factor. Traffic Congestion is the comparison between Traffic per Hour and Road Capacity. It will determine the value of Travel Time Delay and Travel Time. Travel Time Efficiency is the comparison of Travel Time and Travel Time in Free Flow.

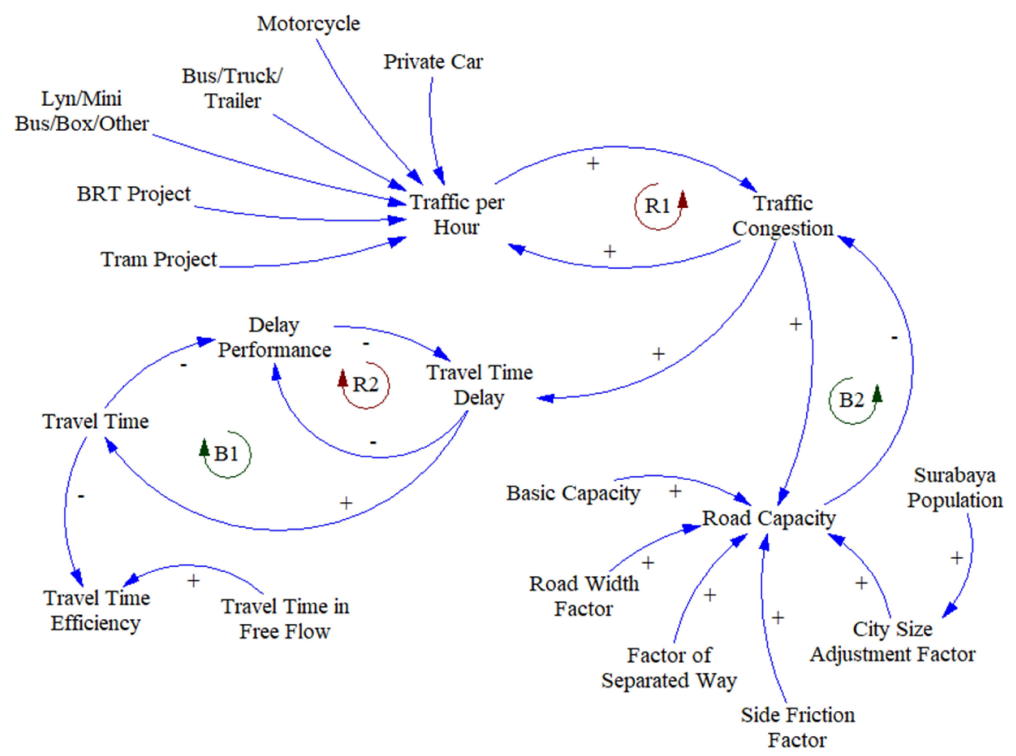

Fig. 1 Causal loop diagram of transport system on Urip Sumoharjo Street, Surabaya

\section{Simulation model development}

CLD is a starting point for numerical simulations. A Stock Flow Diagram (SFD) contains the necessary information for numerical simulations. SFD provides time properties (level, flow, auxiliary variable) to CLD. It holds a dynamic structure by using various icons and arrows. The usage of these icons and arrows is directly connected to differential equation structures [16].

\section{Model validation}

Adequate historical data to cover the time horizon of the simulation is required in the model validation [18]. The timeframe of this simulation is 2000-2020, according to data availability and system behaviuor. Model validation requires to check the error rate and the error variance. A model is valid if the error rate (E1) is below 5\% and the error variance (E2) is below 30\% [19]. The model validation as shown in Equation (2) and (3) as follows:

$$
\begin{array}{r}
E_{1}=\frac{|\bar{S}-\bar{A}|}{\bar{A}} \\
E_{2}=\frac{|\mathrm{Ss}-\mathrm{Sa}|}{\mathrm{Sa}}
\end{array}
$$

where $\bar{S}$ is average of simulation data, $\bar{A}$ is average of historical data, Ss is standard deviation of simulation data, and $\mathrm{Sa}$ is standard deviation of historical data.

The error rate and error variance of some variables such as Motorcycle, Private Car, Lyn/Minibus/Box/Other, and Bus/Truck/Trailer are as shown in Table 1.

\begin{tabular}{|c|c|c|c|c|c|c|}
\hline Variables & $\bar{S}$ & $\bar{A}$ & $\begin{array}{c}\text { Error Rate } \\
\text { (E1) }\end{array}$ & Ss & $\mathrm{Sa}$ & Error Variance (E2) \\
\hline Motorcycle & 182003.10 & 176721.59 & $2.99 \%$ & 25147.13 & 29944.02 & $16.02 \%$ \\
\hline Private Car & 70759.29 & 72259.21 & $2.08 \%$ & 9394.86 & 9241.70 & $1.66 \%$ \\
\hline Lyn/Minibus/Box/Other & 9394.86 & 9241.70 & $1.66 \%$ & 2686.64 & 3275.11 & $17.97 \%$ \\
\hline Bus/Truck/Trailer & 461.00 & 481.10 & $4.18 \%$ & 312.95 & 331.67 & $5.64 \%$ \\
\hline
\end{tabular}

TABLE 1 


\section{E. Scenario (experimentation) development}

Two strategies are implemented to reduce traffic congestion in order to improve commuting time efficiency. The scenarios are developed by modifying the parameters and model structure to shows the impact of various strategies. Bus Rapid Transit (BRT) is an affordable means of transportation that delivers fast and conveniently [20]. The scenario of BRT was developed based on the Surabaya Government's plan to reduce congestion. It was implemented in Surabaya from September to December 2016. The tram development scenario was designed to reduce traffic congestion. This scenario was part of Surabaya Government plans entitled the Surabaya Mass Rapid Transportation (SMART) [12].

The first scenario is BRT and tram projects without highway expansion. The original plan of the tram project would be using one lane of the road for each way. Therefore, the road capacity would decrease with the reallocation of the road space for tramways. The second scenario is BRT and tram projects with highway expansion. According to Ewing and Proffitt [21], the best practice for road capacity expansion is to prioritise new transit projects over addition to regional roadway networks. In this scenario, the road capacity for other transport modes will not be reduced.

\section{RESULTS}

This study shows the impact of strategies that can potentially be implemented to reduce traffic congestion and improve commuting time efficiency. The result section shows the impact of each scenario on traffic congestion and commuting time efficiency. The following analysis shows the comparison between the scenario simulation results and the 'do nothing' simulation results by extending the time horizon of the base model.

A. Bus rapid transit and tram project without highway expansion

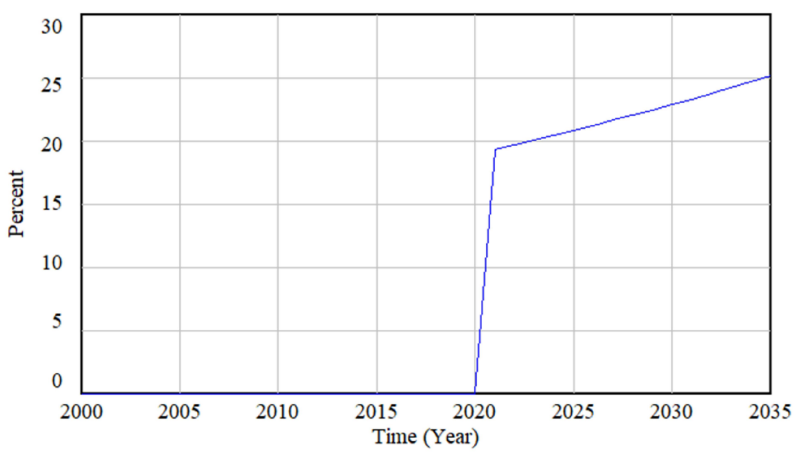

Fig. 2 Percentage of tram users

The percentage of private vehicle users that would switch to tram is projected to be at around $19 \%$ in the first year of implementation and it will continue to grow around $0.19 \%$ annually, see Fig 2 . In the first year of implementation, traffic congestion will grow at around 5\% and commuting time efficiency will decline at around 5\% as shown in Fig. $3-4$. The simulation results have an intersection in 2033, then traffic congestion will decrease at about $2 \%$ and travel time efficiency will grow at around $2 \%$ in 2035.

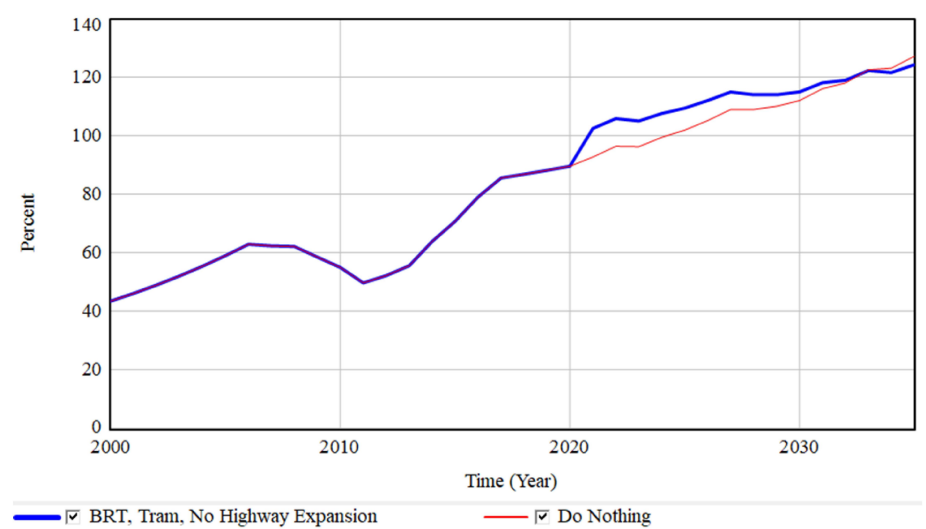

Fig. 3 Comparison of simulation result of traffic congestion for BRT and tram projects without highway expansion scenario 


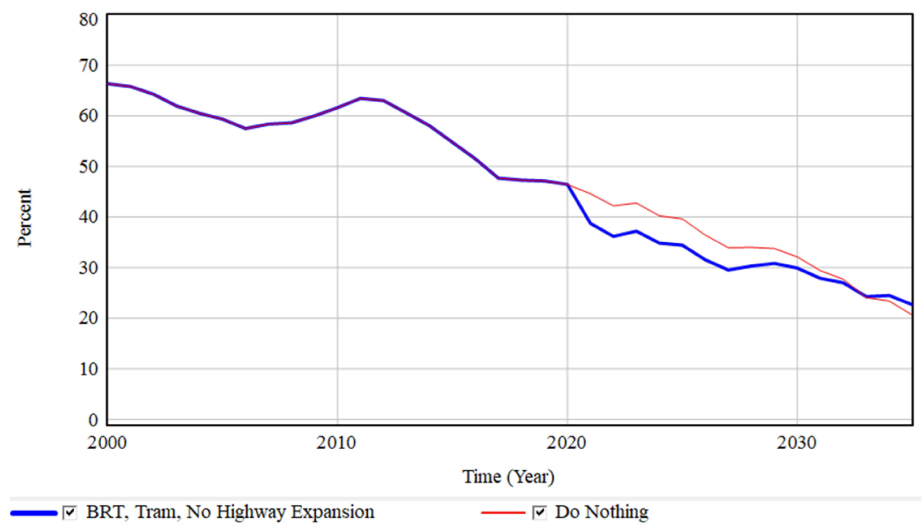

Fig. 4 Comparison of simulation result of travel time efficiency for BRT and tram projects without highway expansion scenario

\section{B. Bus rapid transit and tram project with highway expansion}

The simulation result shows that the implementation without reducing current road capacity could decrease traffic congestion. Traffic congestion is projected to decrease by a minimum of $24 \%$ and a maximum of $44 \%$ as shown in Fig 5. After the implementation, the level of traffic congestion will be kept below $85 \%$, which represents an undersaturated condition. Commuting time efficiency is projected to increase by $11 \%$ in the first year after implementation and by $28 \%$ in 2035 , see Fig. 6 .

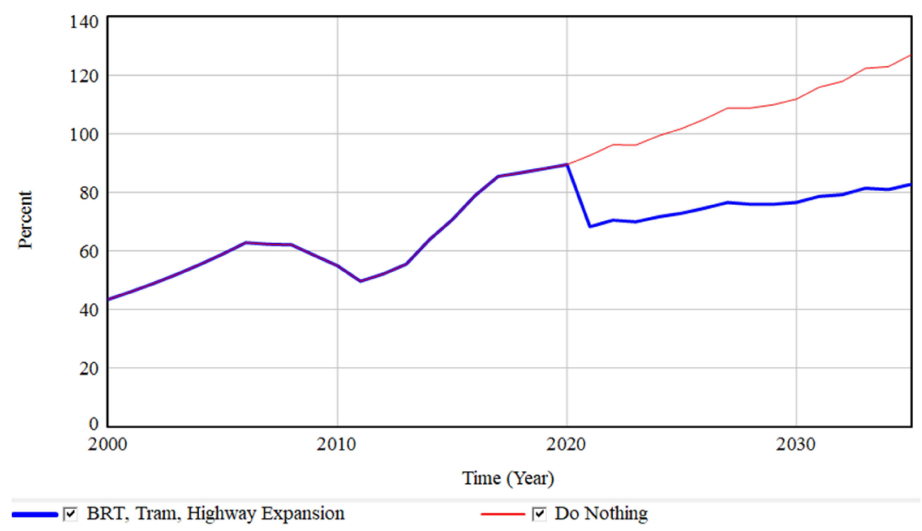

Fig. 5 Comparison of simulation result of traffic congestion for BRT and tram projects with highway expansion scenario

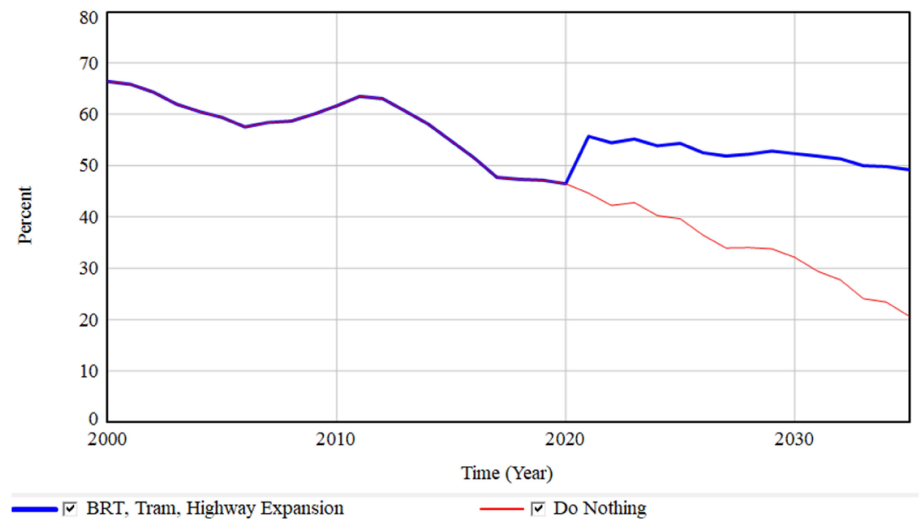

Fig. 6 Comparison of simulation result of travel time efficiency for BRT and tram projects with highway expansion scenario 


\section{DISCUSSION}

The results indicate that BRT and tram projects without additional road capacity will not significantly reduce traffic congestion. Meanwhile, traffic congestion is projected to grow 5\% in the initial year of implementation and only decrease after 2033. This finding is in line with the previous study that predicted that this condition would increase traffic congestion [22]. Both scenarios decrease the number of private vehicles, but the road capacity has a major impact on traffic congestion. This finding is also in line with a statement by Hardiyanti and Rizal [23], which shows that the tram project could decrease vehicle speed on the observed road. The implementation of BRT and tram should be supported by highway expansion so that it will not reduce the current road capacity. The level of congestion could be reduced until below $85 \%$ in the scenario with highway expansion.

The level of traffic congestion shows the comparison between the flow and road capacity per hour. Congestion above $100 \%$ indicates that the traffic flow has exceeded the existing road capacity, resulting in another congestion in connected roads. Increased traffic congestion will prolong commuting time. Commuting time efficiency represents a comparison between the commuting time in free flow and the actual commuting time. If the commuting time efficiency is at $50 \%$, then the commuting time on the observed road is twice the commuting time in free flow. The impact of reduced commuting time efficiency may result in other roads connected to the observed road.

This research is subject to several limitations. The observed road, Urip Sumoharjo, is not a main road with the highest traffic in Surabaya. It was chosen considering the data availability and condition where the tramways and BRT were originally planned.

\section{CONCLUSIONS}

This research was developed to model the impact of the BRT and tram projects on Urip Sumoharjo Street. The objective of these strategies is to improve commuting time efficiency and reduce congestion using the system dynamics model and simulation. The model development is carried out based on the current condition of the actual system. Based on the developed model and scenarios, the number of private vehicles and road capacity have a significant influence on traffic congestion. The reduction in road capacity could increase traffic congestion because the flow will still exceed the road space. Traffic congestion and commuting time efficiency are inversely related. High traffic congestion will decrease commuting time efficiency.

In the initial year of the implementation of tram, around $19 \%$ of private vehicle users will shift to tram and it will continue to grow about $1.9 \%$ annually. BRT and tram projects without highway expansion will decrease commuting time efficiency due to high traffic congestion in the initial year of the implementation. Afterward, the commuting time efficiency will increase by $2 \%$ in 2035 . The project with highway expansion results in declining traffic congestion by $24-44 \%$. With the reduction of traffic congestion, commuting time efficiency will improve by $11-28 \%$. Future research could explore more about transportation system considering some factors such as public transportation investment, infrastructure or accessibility.

[1] Cambridge Systematics Inc, "Traffic congestion and reliability: trends and advanced strategies for traffic congestion mitigation," 2005. doi: 10.1080/10915810500434209.

[2] T. J. Lomax et al., "Quantifying Congestion. Volume 1: Final Report,” Washington, D.C., 1997.

[3] Direktorat Jendral Bina Marga, "Manual Kapasitas Jalan Indonesia (MKJI).” Jakarta, 1997.

[4] R. Akcelik, "Speed-flow models for uninterrupted traffic facilities," Akcelik Assoc. Tech. Rep., no. December 2003, p. 36, 2003.

[5] E. Grison, V. Gyselinck, and J. M. Burkhardt, "Exploring factors related to users' experience of public transport route choice: influence of context and users profiles," Cogn. Technol. Work, vol. 18, no. 2, pp. 287-301, 2016, doi: 10.1007/s10111-015-0359-6.

[6] O. Z. Tamin, Perencanaan dan Pemodelan Transportasi: Teori, Contoh Soal, dan Aplikasi. Bandung: ITB, 2003.

[7] L. Wang, S. Zhang, W. Sun, and C.-L. Chen, "Exploring the physical and mental health of high-speed rail commuters: Suzhou-Shanghai inter-city commuting," J. Transp. Heal., vol. 18, p. 100902, 2020, doi: https://doi.org/10.1016/j.jth.2020.100902.

[8] J. Sterman, Business Dynamics, Systems Thinking and Modeling for a Complex World. McGraw-Hill Inc., 2000.

[9] D. Das and P. Dutta, "A system dynamics framework for integrated reverse supply chain with three way recovery and product exchange policy," Comput. Ind. Eng., vol. 66, no. 4, pp. 720-733, 2013, doi: 10.1016/j.cie.2013.09.016.

[10] S. Wei, H. Yang, J. Song, K. C. Abbaspour, and Z. Xu, "System dynamics simulation model for assessing socio-economic impacts of different levels of environmental flow allocation in the Weihe River Basin, China," Eur. J. Oper. Res., vol. 221, no. 1, pp. 248-262, 2012, doi: 10.1016/j.ejor.2012.03.014.

[11] F. Sugiarto and J. L. Buliali, "Implementasi Simulasi Sistem untuk Optimasi Proses Produksi pada Perusahaan Pengalengan Ikan,” J. Tek. ITS, vol. 1, pp. 236-241, 2012.

[12] P. N. Imani, "Measuring Readiness and Willingness to Pay (WTP) of Surabaya Mass Rapid Transit (SMART), Monorail and Tram: a Survey," J. Tek. ITS, vol. Volume 4, no. 1, 2015.

[13] J. Forrest, "System Dynamics, Alternative Futures, and Scenarios," 1998. 
[14] M. Z. Irawan, "Implementation of the 1997 Indonesian Highway Capacity Manual (MKJI) Volume Delay Function," J. East. Asia Soc. Transp. Stud., vol. 8, pp. 350-360, 2010, doi: 10.11175/easts.8.350.

[15] B. Kiani, M. R. Gholamian, A. Hamzehei, and S. H. Hosseini, "Using Causal Loop Diagram To Achieve a Better Understanding of EBusiness Models," Int. J. Electron. Bus. Manag., vol. 7, no. 3, pp. 159-167, 2009.

[16] Y. Takahashi, "Stock Flow Diagram Making with Incomplete Information about Time Properties of Variables," Proc. 24th Int. Conf. Syst. Dyn. Soc., p. 122, 2006.

[17] E. Suryani, R. A. Hendrawan, F. A. Mukti, and A. Az-Zahra, "System Dynamics Model To Decrease Congestion Cost Using TransitOriented Development,” MATTER Int. J. Sci. Technol., vol. 6, no. 2, pp. 74-89, 2020, doi: 10.20319/mijst.2020.62.7489.

[18] E. Suryani, R. A. Hendrawan, P. F. E. Adipraja, A. Wibisono, and L. P. Dewi, "Urban mobility modeling to reduce traffic congestion in Surabaya: a system dynamics framework," J. Model. Manag., 2020, doi: 10.1108/JM2-03-2019-0055.

[19] Y. Barlas, "Formal aspects of model validity and validation in system dynamics," Syst. Dyn. Rev., vol. 12, no. 3, pp. 183-210, 1996, doi: 10.1002/(sici)1099-1727(199623)12:3<183::aid-sdr103>3.3.co;2-w.

[20] Institute for Transportation and Development Policy, "What is BRT?, 2016.

[21] R. Ewing and D. Proffitt, "Improving decision making for transportation capacity expansion: Qualitative analysis of best practices for regional transportation plans," Transp. Res. Rec., vol. 2568, no. November, pp. 1-8, 2016, doi: 10.3141/2568-01.

[22] Z. Muhis and W. Herijanto, "Manajemen Lalu Lintas Akibat Trem Di Jalan Raya Darmo Surabaya," J. Tek. ITS, vol. 3, no. 1, pp. E37E42, 2014.

[23] F. Hardiyanti and M. C. Rizal, "Studi Biaya Emisi Co Akibat Adanya Rencana Pengembangan Transportasi Massal Cepat (Trem) Di Surabaya," Pros. SENTRA (Seminar Teknol. dan Rekayasa), pp. 1-8, 2017. 